\title{
Psychological inflexibility mediates the relationship between fear of negative evaluation and psychological vulnerability
}

\author{
Erol Uğur ${ }^{1}$ (D) $\cdot$ Çınar Kaya ${ }^{2}$ (D) $\cdot$ Ahmet $\operatorname{Tanhan}^{3,4,5,6}$ (D) \\ Accepted: 17 September 2020 / Published online: 23 September 2020 \\ (C) Springer Science+Business Media, LLC, part of Springer Nature 2020
}

\begin{abstract}
College students worldwide and in Turkey face many biopsychosocial spiritual and economic issues, in part due to developmental and contextual factors. Understanding these issues and their relationship with psychological inflexibility, which is the central concept to the Acceptance and Commitment Therapy (ACT), is an unexplored gap in the literature. Therefore, the aim of the present study is to examine the mediating and moderating roles of Psychological Inflexibility (PI) in the relationship between Fear of Negative Evaluation (FNE) and Psychological Vulnerability (PV), and to set an empirical ground for developing evidence-based research and practices based on ACT. The study group consisted of 389 undergraduate students studying in various departments of a mid-sized urban state university. Regression-based mediation and moderation testing procedures revealed that PI partially mediates the relationship between FNE and PV. Moderating role of PI on the same relationship was not verified. The present findings are deemed to be useful for understanding the relationships of these constructs and developing future mental health research and interventions to address biopsychosocial spiritual issues and enhance wellbeing especially from an ACT perspective.
\end{abstract}

Keywords Psychological inflexibility $\cdot$ Fear of negative evaluation $\cdot$ Psychological vulnerability $\cdot$ Acceptance and commitment therapy $\cdot$ Counseling $\cdot$ Mental health $\cdot$ College students

Stressful life experiences have significant influence on individual's functioning, which may result in anxiety, confusion, withdrawal, depression, and heightened vulnerability (McDonnell and Semkovska 2020; Tanhan 2019; Soares

The author names have been ordered based on their relative contributions to the conduct of the study and preparation of the manuscript. The authors agreed on the order and on all other processes related to the submission of the manuscript.

An earlier draft of this study findings was partially presented as an oral presentation at ERTE Congress: 1st International Education Research and Teacher Education Congress 2017 held in 14th-16th September, in Uşak, Turkey. The manuscript has not been published or sent for publication elsewhere.

Erol Uğur

eugur@ sakarya.edu

Çınar Kaya

cinar.kaya@dpu.edu.tr

Ahmet Tanhan

tanhanahmet3@gmail.com

1 Psychological Counseling and Guidance at the Department of Educational Sciences, Sakarya University, Hendek Campus, 54300 Sakarya, Turkey and Woods 2020). In this respect, vulnerability means that some people are more affected by stressful life events than others (Levine 2004; Shenk et al. 2014), and they may become more vulnerable to psychological problems (e.g., behavioral
Psychological Counseling and Guidance at the Faculty of Education, Kütahya Dumlupınar University, 43100 Kütahya, Turkey

3 Economic and Social Research Center - ESAM, Ankara, Turkey

4 Department of Counseling, The University of North Carolina at Greensboro, Greensboro, NC, USA

5 Department of Counseling, Adiyaman University, Adiyaman, Turkey

6 Institute for Muslim Mental Health, Belleville, MI, USA 
health problems, neglect issues, and emotional impairment). College students worldwide face many biopsychosocial spiritual and economic issues (Becker et al. 2015; Ermis-Demirtas et al. 2018; Haktanir et al. 2018; Kalkan and Griffiths 2018; Karaman and Watson 2017; Krafft et al. 2019; Tanhan and Francisco 2019; Tanhan and Strack 2020). Similarly, college students in Turkey experience different biopsychosocial spiritual and economic issues, in part due to contextual and developmental factors (İkiz et al. 2015; Kızıldağ et al. 2012; Tanhan 2020; Tanhan et al. 2020a). College students in Turkey seem to be vulnerable to many biopsychosocial spiritual and economic issues. Therefore, some researchers called for empirical research on psychological inflexibility, stress, and anxiety to enhance wellbeing of individuals (Tanhan 2019; Tanhan et al. 2020b).

\section{Psychological Vulnerability (PV)}

Psychological vulnerability indicates detrimental cognitive patterns in which one is in constant search of approval for their sense of self-worth (Sinclair and Wallston 1999). Therefore, psychological vulnerability can lead to dysfunctional or less functional patterns of cognitions, feelings, and behaviors (e.g., passivity, self-blame, isolation, and catastrophizing), which can lead to psychopathology or decreased psychological well-being (Sinclair and Wallston 1999). People with psychological vulnerability also suffer from more psychological distress (Romero-Moreno et al. 2013; Sinclair and Wallston 1999). Maladaptive coping and cognitive emotion regulation strategies such as behavioral avoidance and dysfunctional attitudes are some of the vulnerability factors for depression, anxiety and suicidal tendency (Choi et al. 2015; Morris et al. 2014). There are significant associations between psychological vulnerability and maladaptive coping behaviors of passivity, self-blame, isolation, catastrophizing, and perceived helplessness (Romero-Moreno et al. 2013; Sinclair and Wallston 1999). People with psychological vulnerability have restricted capacity to cope with stressors (Clark et al. 2007; Mehrabian 1995) and perceived control over undesired emotional experiences. In this regard, they are at a higher risk to experience stressful life events in a more excessive manner (Raines et al. 2014).

Psychological vulnerability has interrelations with various psychological states and constructs. Researchers found that psychological vulnerability was positively associated with anxiety, stress (Cox et al. 2001), self-alienation (Satici et al. 2013), and social vulnerability (Sarıçam 2015). Psychological vulnerability was also a predictor of the level of pain (Hansen et al. 2015). On the contrary, psychological vulnerability had negative correlations with social competence, mindfulness, insight and resilience factors like social support, self-efficacy (Akin 2014; Gruebner et al. 2015; Kiamarsi and Abolghasemi 2014; Satici et al. 2014), learned resourcefulness, and authentic living (Sertbaș 2014). Tanhan and others (2020b) reported that college students in Turkey have a higher level of psychological vulnerability and psychological inflexibility. In a recent Online Photovoice (OPV) study, the researcher found college students experience many biopsychosocial spiritual and economic issues during COVID19 (Tanhan 2020). All these researchers also called for further robust research focusing on these and other related constructs. Based on all these findings, it is important to examine the relationship of psychological vulnerability with other related constructs including psychological inflexibility and fear of negative evaluation among the college students.

\section{Psychological Inflexibility (PI)}

Seeing one's thoughts, feelings, and sensations as they are could be a key component for addressing psychopathology and promoting wellbeing (Hayes et al. 2012; Larson 2011; Tanhan 2019). ACT is one of the third-wave therapies that represent a multidimensional and functional contextual model both for wellbeing and abnormal psychology (Hayes et al. 2006; Hayes et al. 2012; Tanhan 2019; Twohig 2012). From an ACT perspective, pain as a natural response to unwanted or unenjoyable situations turns into psychopathology or suffering through PI processes (McCracken and Vowles 2007; Tanhan 2019). PI consists of dysfunctional control efforts that are named as the six core psychological inflexibility processes: experiential avoidance, inflexible attention, disrupted values, inaction or impulsivity, conceptualized self, and cognitive fusion (Hayes et al. 2006; Hayes et al. 2012; Levin et al. 2014).

A person who experiences intense pain through one or more of these six core processes, considering this person's limited individual resilience capacity, is more likely to gradually develop PI which may in turn lead to psychopathology (Tanhan 2019). The experiential avoidance plays a central role in PI and is an example for primordium of psychological inflexibility (Bond et al. 2011). Experiential avoidance means a person's effort to stay away from providing room for one's experiences (e.g., thoughts, feelings, sensations) and this leads to more suffering; in other words, experiential avoidance emerges when the person is not willing to give space to inner pleasant or unpleasant experiences (Hayes et al. 2006, 2012; Tanhan 2019). When the person applies this avoidance or other core processes by themselves or in combination at extreme levels, then it is highly likely that the unwanted experiences turn into psychological problems through PI over time (Greco et al. 2008; Hayes et al. 2012; Tanhan 2019).

Some other researchers used different terminologies that go well with the above mentioned ACT's Psychological Inflexibility (PI) term. For example, Gawda (2017) used ognitive inflexibility (intolerance of ambiguity, dogmatism or need for closure) and some other researchers (Webster 
and Kruglanski 1994) used a similar concept that is cognitive closure (i.e., desire for predictability, preference for order and structure, discomfort with ambiguity, decisiveness, and closed-mindedness). These terminologies are similar with the six core processes of PI and have a significant conceptual overlap with PI. Considering the behavioral expressions of these concepts, it can be said that they can be an indicator of PI. For example, although PI is similar to cognitive inflexibility in terms of behavioral expressions, PI is linked to health and well-being and is an identified treatment outcome for therapies such as ACT. Cognitive inflexibility can be defined as the disability to flexibly adjust a behavior to the demands of the changing environment (Armbruster et al. 2012).

PI is characterized by limited behavioral repertoire and includes intolerance to ambiguity (Furnham and Marks 2013). In this study, the behavioral characteristics of the concept of intolerance to ambiguity point to the symptoms of PI. So that intolerance to ambiguity may be considered as a part of PI. These behavioral features serve PI. The overuse of these rigid strategies narrows one's behavioral alternatives, possibilities for positive experiences, and increases distress in the long term that means psychological dysfunction (Bond et al. 2011; Hayes et al. 2006; McCracken and Vowles 2007; Tanhan 2019; Williams et al. 2012).

There are significant associations between PI and a broad range of psychological disorders that are characterized by the dominance of avoidant response style (Bond et al. 2011). Researchers found the association among the restrictive nature of psychological inflexibility, somatization, depression, and anxiety (Harris 2009; Masuda and Tully 2012) and PTSD (Dick et al. 2014).

As opposed to the PI model, ACT utilizes the psychological flexibility model to address how natural responses develop wellness through the flexibility model (Hayes et al. 2006, 2012; Tanhan 2019). Psychological flexibility model comprises six core processes (i.e., acceptance, flexible attention to the present moment, values, committed action, self-as-context, defusion). Psychological flexibility is a mediator of changes in self-compassion, anxiety, depression, stress and general psychological distress (Yadavaia et al. 2014), positively related to the psychologically resilient outcomes (Galatzer-Levy et al. 2012), and decreases in PTSD symptoms (Dick et al. 2014). Based on all these findings, it is important to examine PI as a construct from an ACT perspective and its relationship with psychological vulnerability among college students in Turkey.

\section{Fear of Negative Evaluation (FNE)}

Fear of Negative Evaluation (FNE), highlighted as an inherent component of social anxiety, is constant and excessive anxiety (Weeks et al. 2008). Watson and Friend (1969) defined FNE as a measure of social anxiousness, the worry an individual might have toward negative evaluation, and also the hesitation that others would evaluate him negatively. FNE accompanies social anxiety, and it is characterized by being overly concerned with others' appreciations and hiding one's undesirable feelings (Watson and Friend 1969; Bilge and Kelecioğlu 2008).

FNE is an indicator of psychological functioning and adjustment. FNE has an important role on stress, anxiety, interpretation biases, and psychological well-being (Dryman and Heimberg 2015; Nonterah et al. 2015). Individuals who have fear of being negatively evaluated avoid social interactions requiring social performance. They resort to rigid strategies to feel safe and avoid rejection from others. Indeed, they try to look for safe behaviors to stay away from negative evaluation and criticism that might lead to suffering for them (Çetin et al. 2010; Rapee and Heimberg 1997). Such rigid coping behaviors, coupling with the claim for a positive impression, lead to vulnerability to psychological dysfunctioning and finally result in a vicious circle (Fay et al. 2008; Nonterah et al. 2015). Excessive coping patterns can play detrimental roles in psychological adjustment (Kornienko and Santos 2014). Additionally, people's concern about how they are evaluated by others has a restrictive effect on their social and psychological functioning (Bilge and Kelecioğlu 2008; Rapee and Heimberg 1997).

Individuals with low level of FNE are less anxious about evaluations. There is a significant relationship between lower levels of FNE and reduction in depressive symptoms (Kornienko and Santos 2014). On the other hand, high level of FNE has detrimental effects on individuals' mental health (Button et al. 2015). Individuals with higher levels of FNE have increased vulnerability. They fear the loss of social appreciation. They are more inclined to make inaccurate explanation of neutral expressions and exhibit higher levels of distress in comparison to people with lower levels of FNE (Nonterah et al. 2015; Winton et al. 1995). People with higher levels of FNE are more likely to interpret ambiguous social situations in a detrimental manner (Dryman and Heimberg 2015). When FNE is at a high level, it may lead to social withdrawal. Thus, people with higher levels of FNE might not develop healthy communication skills such as being respectful, clear, concrete and empathic, which are very functional for enhancing healthy interpersonal relationships. Such a cycle of causality is more likely to result in unhappiness (Button et al. 2015; Karabulut and Bahadır 2013).

\section{Psychological Inflexibility (PI) as a Mediator}

Empirical and theoretical research based on ACT perspective indicate that PI acts as a mediator in different studies. Research about ACT interventions has pointed to the ability 
to reduce PI through therapy (Hayes et al. 2012; Tanhan et al. 2020a). PI can be conceptualized as a global behavioral pattern of effortful avoidance in attempt to down-regulate unwanted emotional experiences, combined with the rigid adherence to literal content of thoughts (Hayes et al. 2006; Hayes et al. 2011b; Mendoza et al. 2018). The idea of a mediational variable that could explain why this relationship exists emerged from research in which experiential avoidance was regularly implicated in the literature examining both fear of negative evaluation and psychological vulnerability.

A considerable number of results support the mediating role of PI. In a recent study with 451 adults in Turkey, researchers found that psychological inflexibility mediated the relationship between stress and psychopathology including depression, somatization, and anxiety (Arslan et al. 2020). For example, Yadavaia and their friends (2014) pointed out that PI is a mediator of changes in self-compassion, anxiety, depression, stress and general psychological distress. PI mediates also the relationship between depression severity and stigma toward others with depression (Gaudiano et al. 2017); the relationship between perceived workplace demands and psychological distress (Kurz et al. 2014); the relationship between adverse childhood experiences and mental health outcomes (Makriyianis et al. 2019); the relationship between perfectionism and religiosity (Crosby et al. 2011); the positive associations between self-concealment and distress variables (Mendoza et al. 2018).

College students in Turkey face many issues due to contextual and developmental factors (İkiz et al. 2015; Karaman et al. 2020; Kızıldağ et al. 2012; Tanhan 2020; Tanhan et al. $2020 \mathrm{a}, \mathrm{b})$. Therefore, it is crucial to understand the college students because they seem to be vulnerable to many biopsychosocial, spiritual and economic issues. In a quasiexperimental study, 133 college students received a fivesession counseling service and their quality of life increased through decreased PI level compared to the control group (Tanhan et al. 2020a). The researchers called for further examination of PI among college students in Turkey in relation to other issues the students experience [e.g., stress, anxiety, feeling overwhelmed with courses, sociopolitical conflicts in the area (Tanhan et al. 2020a, b). Therefore, it is important to understand the relationship of PI with FNE and psychological vulnerability among the college students.

\section{Purpose of the Present Study}

The aim of the present study is to investigate the mediating and moderating roles of PI on the relationship between FNE and psychological vulnerability among college students in Turkey. An individual with high PI, as described within the ACT theoretical framework, might be more likely to develop high levels of psychological vulnerability in the face of FNE.
ACT shows how psychopathology gradually occurs through PI model (Hayes et al. 2006, 2012; Tanhan 2019). The model consists of six core processes and it shapes therapeutic change and wellness (Harris 2009; Hayes et al. 2011a). Researchers called for examining PI and its relationship with other constructs among college students in Turkey for more robust grounded research and mental health services (Tanhan et al. 2020a, b), which make this study important as it examines the role of PI as a mediator.

\section{Method}

\section{Participants}

The study group consisted of 389 undergraduate students who agreed to participate. They were studying in various departments of a mid-sized urban state university in Turkey. The group consisted of 207 females $(53,2 \%)$ and 182 males (46,8\%) whose ages ranged from 17 to 35 ( $M=22,41$ years). Volunteering participation, informed consent, participant privacy, and anonymity procedures were all compliant with the local institutional standards of the department regarding crosssectional anonymous survey studies with no manipulation involved. Some students who were informed about the study did not participate due to different reasons (e.g., lack of time, being tired, not willing to particate) when a research assistant asked for participation and provided the printed survey package in classes and gathering points (e.g., library). The research assistant who provided information and the package to the students has not been part of the study to protect voluntary participation. The study procedures were approved by the respective authorities and are compliant with the ethical standards set by the updated version of the Declaration of Helsinki (64th WMA General Assembly, Fortaleza, Brazil, October 2013). The participants filled the scales in printed forms. Inappropriately or insufficiently filled data (12 cases), and multivariate outliers ( 2 cases based on Mahalonobis scores) were excluded.

\section{Procedure}

The aim of the current study is to examine the mediating and moderating roles of PI in the relationship between FNE and psychological vulnerability. The regression-based procedures recommended by Baron and Kenny (1986) for testing mediation and moderation were used. Although their step-based procedures and distinction of partial and full mediation are deemed as outdated in mediation research (Hayes 2018), these procedures have potential merit as a preliminary analytic procedure. PROCESS macro (Hayes 2013) was utilized for testing the mediation and moderation effects; calculating the magnitudes and the significance levels of the effects with 
bootstrapping and Sobel tests. Independent variable of the study (the X variable) was FNE; and the dependent variable (Y variable) was psychological vulnerability; and PI was the possible mediator and moderator variable ( $\mathrm{M}$ variable). The mediation model was tested by a Structural Equation Modeling (SEM). All the variables were included in the model as latent variables linked to the scale items, including the measurement model. In SEM, degree of convergence between the theoretical model and the structure of the data in question is assessed by calculating several fit indices. The foremost of those is Chi-Square $\left(X^{2}\right)$, which is usually divided by the degree of freedom. Although with different focuses and formulas, SRMR, RMSEA, CFI, and TLI and similar fit indices serve the same purpose (Kline 2015). Based on the rules of thumb suggested in the related literature, $X^{2} / \mathrm{df}$ ratio is deemed acceptable below 3 (Schermelleh-Engel and Moosbrugger 2003); SRMR is regarded acceptable within 0 to 1 range (Brown and Cudeck 1993). RMSEA is regarded as acceptable below .08 (Byrne and Campbell 1999). CFI and TLI (also as Non-Normed Fit Index; NNFI) is regarded as acceptable above 90 (Bentler and Bonett 1980; Schermelleh-Engel and Moosbrugger 2003). All statistical analyses were conducted on the SPSS 21.0 and AMOS 20 software packages.

\section{Measures}

Acceptance and Action Questionnaire-II (AAQ-II) Level of PI was measured using the AAQ-II (Bond et al. 2011). The AAQ-II measures one's tendency toward excessive control of thoughts and feelings and the ability to act in the presence of aversive thoughts or feelings (Landstra et al. 2013). Turkish adaptation of this scale was done by Yavuz et al. (2016). The AAQ-II is a 7-item self-report instrument and each item is rated on a 7-point scale. All answers are summed up to find the tendency level of PI, with higher scores indicating greater levels of PI. Results of the exploratory factor analysis demonstrated that the seven items loaded on one factor which explains $61.8 \%$ of the total variance. Cronbach's alpha internal consistency reliability coefficient was .90 and the correlation between test-retest (after 2 weeks) was $r=.85$. The corrected item-total correlations ranged from .63 to .77 . The results of convergent validity analysis demonstrated that the total score of AAQ-II had significant positive relationships with total scores of Ruminative Thinking Style Questionnaire, Beck Depression Inventory, and The State-Trait Anxiety Inventory ( $r=.56, r=.63, r=.65$ respectively). The alpha internal consistency reliability coefficient was .84 in the present study, which indicates a good internal consistency. The CFA conducted on the data utilized in the present study indicated acceptable levels of construct validity $\left(x^{2}=67.65, \mathrm{df}=14\right.$, RMSEA $=.099, \mathrm{NFI}=.92, \mathrm{CFI}=.94, \mathrm{AGFI}=.90$, and $\mathrm{TLI}=.90)$.
Psychological Vulnerability Scale (PVS) PVS was developed (Sinclair and Wallston 1999) as a self-report instrument to measure a set of cognitions that trigger maladaptive reactions to stress. PVS consists of 6 items and each item is rated on a 5point Likert scale ( $1=$ unsuitable to me, $5=$ definitely suitable to me). The scale is interpreted through total scores from 5 to 35 where higher scores indicate higher levels of psychological vulnerability. Turkish adaptation of PVS was conducted by Akın and Eker (2011). The results of the confirmatory factor analysis indicated that the model fitted the data well $\left(x^{2}=\right.$ 7.82, df $=9$, RMSEA $=.000, \mathrm{NFI}=.97, \mathrm{CFI}=1.00$, $\mathrm{GFI}=.99, \mathrm{AGFI}=.98, \mathrm{RFI}=.95$, and $\mathrm{SRMR}=.025)$. Factor loadings of PVS items ranged from .46 to .69. The Cronbach's alpha for PVS was .75 and the corrected item-total correlations ranged from .26 to .44 . In the present study, the alpha coefficient was .69, which is questionable; and the CFA results indicated good levels of construct validity of PVS $\left(x^{2}=\right.$ $25.31, \mathrm{df}=9, \mathrm{RMSEA}=.068, \mathrm{NFI}=.93, \mathrm{CFI}=.95$, $\mathrm{AGFI}=.95$, and $\mathrm{TLI}=.91)$.

The Brief Fear of Negative Evaluation Scale (BFNES) BFNES was developed by Leary (1983) and adapted into Turkish by Çetin et al. (2010). BFNES is a self-report scale devised for measuring the (in)tolerance of the individuals in case of negative or hostile evaluations about themselves from others (Karabulut and Bahadir 2013). The scale is based on a five point Likert type scale with 11 items. According to confirmatory and exploratory factor analysis, the researchers found a one-factor model which is in line with the Turkish sample, explaining \%40.19 of the total variance. The correlation between test-retest (after 2 weeks, 76 participants) was $r=.82$. The Cronbach's alpha coefficient of the questionnaire was .84 , and the split-half reliability coefficient was .83 . For the present study, the alpha coefficient was .83 that indicates a good internal inconsistency. The CFA results with a slightly modified model (with one modification by drawing a covariance between errors of item 2 and 6 which depict similar target behaviors) indicated acceptable levels of construct validity of BEFNES $\left(x^{2}=210.67, \mathrm{df}=43, \mathrm{RMSEA}=.100, \mathrm{NFI}=.87\right.$, $\mathrm{CFI}=.89$, $\mathrm{AGFI}=.85$, and $\mathrm{TLI}=.86)$.

\section{Results}

Normality of the distributions were ensured and two cases were omitted in the analysis procedures due to multivariate outliers based on the Mahalonobis distance values. Reliability coefficients, means, standard deviations, skewness, kurtosis values and inter-correlations among variables are presented in Table 1. The descriptive analysis has shown that the variables had normal distributions. As for zero-order Pearson Correlation coefficients, PI was significantly related with 
Table 1 Inter-correlation and descriptive statistics

\begin{tabular}{|c|c|c|c|c|c|c|c|c|}
\hline & 1 & 2 & 3 & Mean & Std. Dev. & Alpha & Skewness & Kurtosis \\
\hline 1. PI & & & & 26.37 & 9.49 & .84 & -.01 & -.77 \\
\hline 2. FNE & $.47 * *$ & & & 30.78 & 8.24 & .83 & .18 & .04 \\
\hline 3. PVS & $.51 * *$ & $.57 * *$ & & 16.64 & 5.02 & .69 & .22 & -.32 \\
\hline
\end{tabular}

$* * p<.001$

FNE $(r=.47, p<.001)$; and psychological vulnerability $(r=.51, p<.001)$.

\section{Testing Mediation}

In testing the mediation effects, firstly the relationship between the independent variable (FNE) and proposed mediator (PI) was tested. Regression results are presented in Table 2. FNE related positively with PI $(\beta=.47, t=10.39, p<.001)$.

Secondly, the relationship between the proposed mediator (PI) and dependent variable (psychological vulnerability) was tested. Psychological inflexibility related positively with psychological vulnerability $(\beta=.51, t=10.39, p<.001)$. Regression results are presented in Table 3.

Finally, the relationship between the independent variable (FNE) and dependent variable (psychological vulnerability) was tested without (Step 1) and with (Step 2) the mediator. The regression analysis in Step 1 revealed that the FNE was positively related to psychological vulnerability $(\beta=.57, t=$ $13.76, p<.001)$. When PI entered into the regression, the regression coefficient for the FNE decreased in Step 2; yet it was still significant $(\beta=.26, t=9.65 ; p<.001)$. The results are shown in Table 4.

These results are typical indicators for a partial mediation. In order to test the significance of the mediational effect of PI in the relationship between fear of negative evaluation and psychological vulnerability, bootstrapping and the Sobel Z test were conducted, and effect sizes were calculated by the PROCESS macro. The indirect coefficient effect was .088 $(\mathrm{SE}=.01)$, significantly different from zero in a $95 \%$ biascorrected bootstrap confidence interval, and ranged from .059 (BootLLCI) to .123 (BootULCI). Preacher and Kelley (2011) compared and contrasted various measures of mediation effect size and concluded that Kappa Squared value

Table 2 Fear of negative evaluation and psych. inflexibility

\begin{tabular}{llcll}
\hline Variable & $B$ & $S E_{B}$ & $\beta$ & $t$ \\
\hline Fear of Neg. Ev. & .54 & .05 & .47 & 10,39 \\
\hline
\end{tabular}

DV: Psych. Inflexibility $p<.001, R=.47, R^{2}=.21$ fulfills the most of their evaluation criteria. In this study, Kappa squared indirect coefficient effect was .156 $(\mathrm{SE}=.03)$, ranging from .108 (BootLLCI) to .205 (BootULCI). Normal theory based Sobel Z test (Sobel 1982) also revealed that the partial mediation effect was significantly different from zero in parallel with the bootstrapping results $(Z=5.743, p<.001)$. Figure 1 represents the regression results embedded in the conceptual diagram.

\section{Confirming Mediation}

An SEM analysis was conducted for confirming the mediation model which had preliminary support for total score and regression-based procedures. Complying with the mediation approach, fear of negative evaluation was the exogenous variable, and psychological vulnerability and the mediating PI were the endogenous variables. The error terms for three items of FNE (c2, c6 and c9) were covariated in the model for the fact that they were all negatively worded items which had a great level of convergence in meaning. The results of the SEM analysis have shown that the model fitted the data in acceptable levels $\left(x^{2}=539.346, \mathrm{df}=246, x^{2} / \mathrm{df}=2.19\right.$, RMSEA $=.055$, SRMR $=.050$, TLI $=.90$, CFI $=.91$, $\mathrm{IFI}=.91, \mathrm{RFI}=.82)$. The model and the results are shown in the path diagram in Fig. 1.

When Fig. 2 is examined, it is seen that FNE had a positive relationship with PI $(\lambda=.60, p<.001)$; PI had a positive relationship with psychological vulnerability $(\lambda=.24, p$ $<.001)$, and FNE had a positive relationship with psychological vulnerability $(\lambda=.67, p<.001)$. Another SEM model assuming full mediation was also tested. In this model where there were no regression paths defined from FNE to vulnerability, the model fit values were less acceptable compared to the partial mediation model $\left(X^{2}=637.712, \mathrm{df}=247\right.$,

Table 3 Psych. inflexibility and psych. vulnerability

\begin{tabular}{lcccc}
\hline Variable & $B$ & $S E_{B}$ & $\beta$ & $t$ \\
\hline Psych. Inflex. & .27 & .02 & .51 & 11.62 \\
\hline
\end{tabular}

DV: Psych. Vulnerability $p<.001, R=.51, R^{2}=.26$ 
Table 4 Testing the mediation

\begin{tabular}{lcccccc}
\hline Variable & $B$ & $S E_{B}$ & $\beta$ & $t$ & $p$ & $R^{2}$ \\
\hline Step 1 & & & & & & \\
Fear of Neg. Ev. & .35 & .03 & .57 & 13.76 & .00 & .33 \\
Step 2 & & & & & & \\
Fear of Neg. Ev. & .26 & .03 & .43 & 9.65 & .00 & \\
Psych. Inflexibility & .16 & .02 & .31 & 6.92 & .00 & .40 \\
\hline
\end{tabular}

DV: Psych. Vulnerability, $\Delta R^{2}=.07$

$X^{2} / \mathrm{df}=2.58, \mathrm{RMSEA}=.064, \mathrm{SRMR}=.072, \mathrm{TLI}=.87$, $\mathrm{CFI}=.88, \mathrm{IFI}=.88, \mathrm{RFI}=.80$ ). This also supports a partial mediation of PI on the relationship between FNE and psychological vulnerability.

\section{Testing Moderation}

For testing the possible moderating role of PI in the relationship between FNE and psychological vulnerability, the following steps were taken: First, as in the Step 2 of the moderation analysis, the independent variable and the moderator were regressed on the dependent variable (Model 1). Secondly, an interaction term was created by multiplying the scores of the independent variable (namely FNE) and the possible moderator (PI). Then this interaction variable (FNE X $\mathrm{PI})$ was entered into the regression equation together with scores of FNE and PI (Model 2). The interaction variable was not significantly related to psychological vulnerability $(B=.01, t=1.86, p>.05)$, and Model 2 did not significantly increase the variance accounted in the dependent variable $\left(\Delta R^{2}=.01, p>.05\right)$. In the bootstrapping analysis with Hayes' PROCESS Macro, moderating effect was not also verified. Interaction term FNE had a coefficient of .004 $(\mathrm{SE}=.002)$. This was not significantly different from zero in a $95 \%$ bias-corrected bootstrap confidence interval and ranged from -.0002 (BootLLCI) to .0089 (BootULCI). These results show that the moderating role of $\mathrm{PI}$ in the relationship between FNE and psychological vulnerability does not exist.

\section{Discussion}

In the current study, we found the mediating role of PI in the relationship between FNE and psychological vulnerability. The findings overall fit into the larger literature (e.g., Arslan et al. 2020) stating that PI acts as an important mediator between different constructs (e.g., depression, anxiety). Despite the presumed positive links between FNE, PI, and psychological vulnerability, little is known about the factors that might mediate these relationships, which makes this study unique. This is a preliminary work for understanding the roles of FNE and psychological vulnerability, and how PI might require more research attention. Our findings may serve as a cue which would explain why it is functional to reduce PI and improve approaches and techniques to give space to one's desired or undesired experiences. Such an acceptance process might gradually improve effective coping strategies and address psychological disorders. There are a few main points worth discussing.

Before delving into the implications, it is useful to stress on the statistical procedures and their possible role in corroborating the findings. In terms of the analytical framework, we employed a three-step test for the mediation, and a two-step test for the moderation. Baron and Kenny's (1986) recommendations were followed to better substantiate the model. A bootstrapping method was utilized further to test the mediating role found in the first step. In the last step, SEM approach was adopted with an embedded measurement model in order to further confirm the mediation with a rather nonreductionist approach (i.e., taking all the errors and relationships of the individual items into account, rather than working
Fig. 1 Mediating role of psychological inflexibility in the relationship between FNE and psychological vulnerability

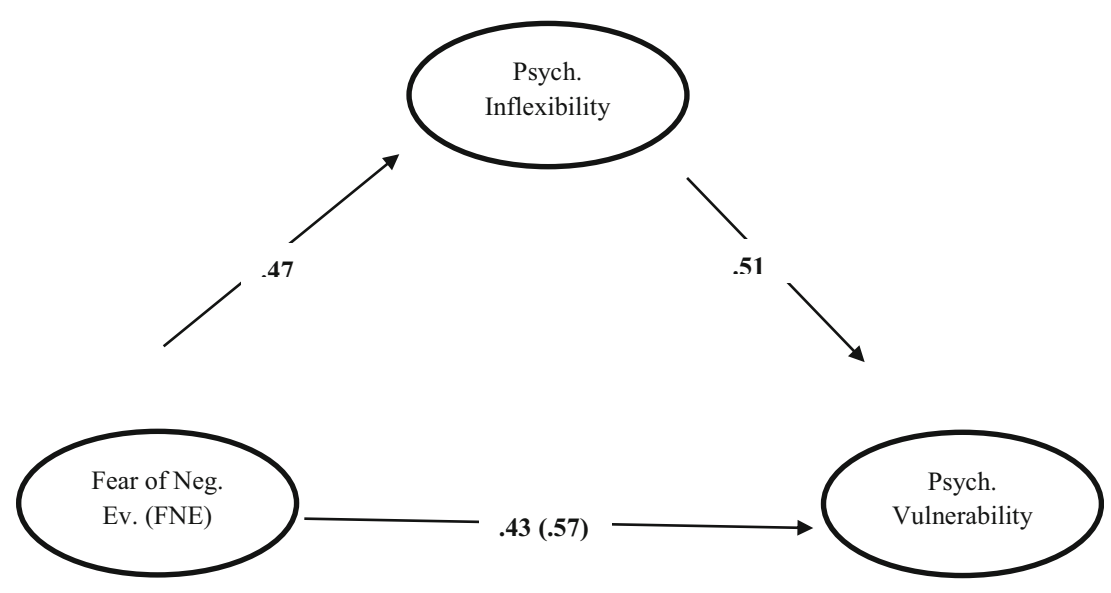




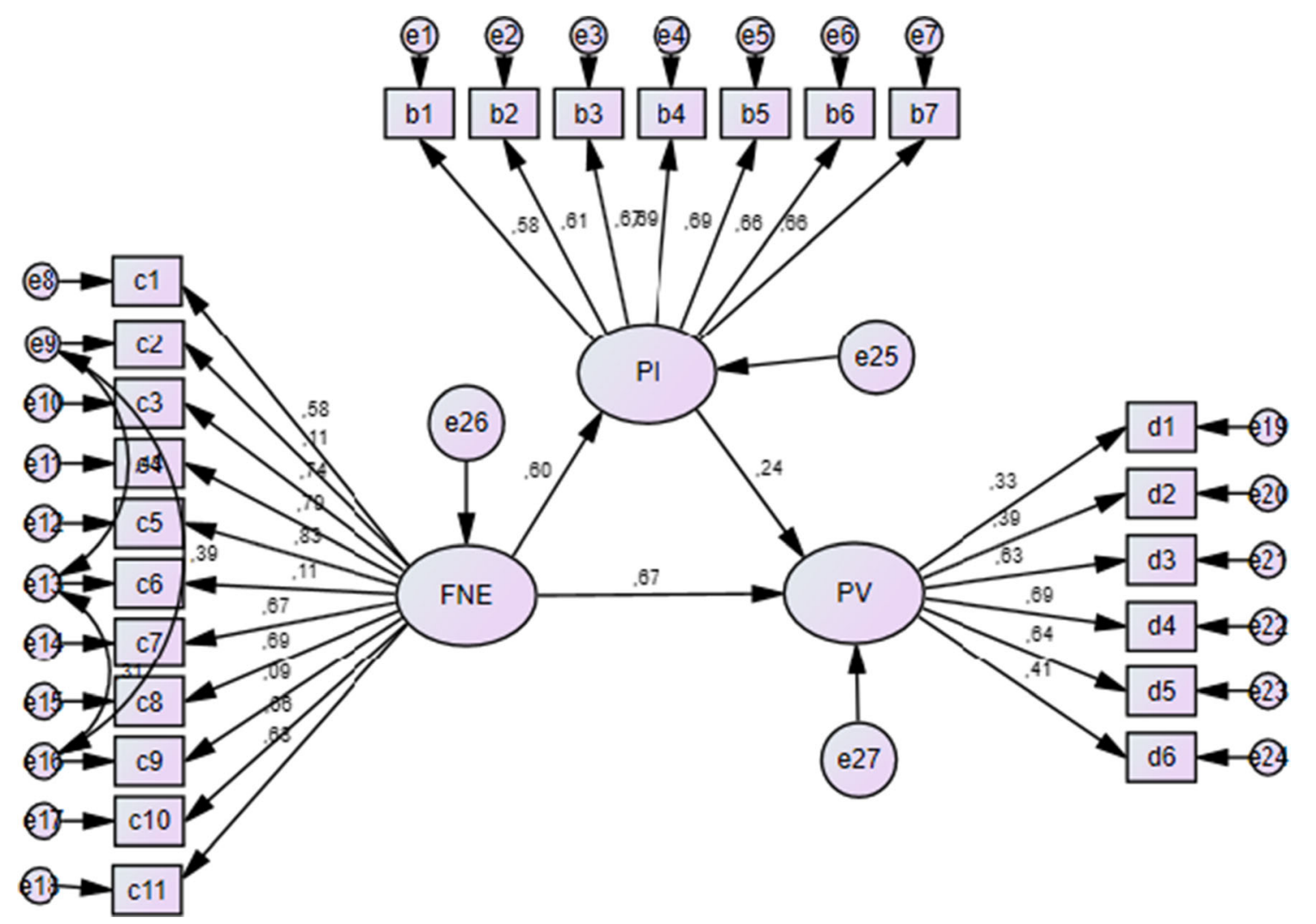

Fig. 2 Path diagram with standardized estimates

with summed scores). In terms of moderation, the two steps of simple regression-based analysis and bootstrapping analysis were conducted.

First, FNE was positively related to PI in our work. This finding is consistent with previous studies that revealed the association between PI and anxiety disorders (Arslan et al. 2020; Harris 2009; Masuda and Tully 2012). Fear of negative evaluation is a strong risk factor for social anxiety, and having more psychological flexibility becomes more important to cope with the fear of negative evaluation effectively. People who have high levels of FNE desire to make a favorable impression (Heimberg et al. 2010) with high levels of emotional arousal (McManus et al. 2008), so they may lose their full contact with the present moment and use maladaptive coping strategies. The use of maladaptive coping strategies at an intense level may lead to a psychopathological PI in a vicious circle (Tanhan 2019).

Second, FNE was positively related to psychological vulnerability. With respect to their nature, this meaningful relationship seems usual. Individuals with higher level of FNE may be overly concerned with others' appreciations and hiding the undesirable feelings (Bilge and Kelecioğlu 2008; Watson and Friend 1969). Similarly, people with psychological vulnerability have dependency for approval from others and may develop unreal expectations. In order to satisfy these expectations, people may tend to use rigid and dysfunctional coping behaviors of passivity, self-blame, isolation, and catastrophizing which, in turn, can lead to decreased psychological well-being (Sinclair and Wallston 1999). Indeed, both people with high FNE and psychological vulnerability give much more attention to others' opinions and feedbacks.

Third, as presumed, PI predicted psychological vulnerability in a positive way. Likewise, in PI, people with psychological vulnerability have maladaptive cognitive networks which render them more delicate to stress (Sinclair and Wallston 1999). In ACT, when a person believes these dysfunctional cognitive networks and treats them as real rather than cognitions or feelings then this process is called cognitive fusion which refers to the undesirable functions of thoughts (Hayes et al. 2006; Hayes et al. 2012; Tanhan 2019). People who have cognitive fusion may be more susceptible to PI. In accordance with this, it can be said that people who have higher levels of PI may get inclined to psychological vulnerability which includes more distress, negativity, and failure (Hayes et al. 2006; Hayes et al. 2012; Romero-Moreno et al. 2013; Tanhan 2019).

Finally, the relationship between FNE and psychological vulnerability was partially mediated by PI. The partial mediation was both supported in the regression-based analysis and further confirmed in the SEM results. PI promotes negative outcomes including more psychopathology and less satisfying life (Larson 2011; Tanhan et al. 2020a). Likewise, in FNE, PI 
also contains excessive and rigid psychological reactions which stem from dysfunctional control efforts (Levin et al. 2014). In other words, individuals who have higher level of PI tend to use such dysfunctional coping strategies more (e.g., experiential avoidance, not being in the present moment, and suppressing emotions; Hayes et al. 2006; Tanhan 2019). These excessive behavioral patterns seem likely to result in significantly decreased adjustment in the long run (McCracken and Vowles 2007), and people who have restricted behavioral repertoire may feel more psychological vulnerability. Additionally, dysfunctional coping and cognitive emotion regulation strategies such as behavioural avoidance and adopting safety behaviors which are associated with psychological vulnerability are some of the factors for depression, anxiety and suicidal tendency (Choi et al. 2015; Morris et al. 2014).

The findings of the current study revealed that PI has meaningful correlation with FNE and psychological vulnerability. PI takes an important place in this association. The relationship between negative evaluation and psychological vulnerability was mediated partially by PI which is the principal source of psychological difficulties according to the ACT perspective. ACT utilizes psychological flexibility processes during mental health services to empower clients through each of the processes and cultivate wellbeing or address biopsychosocial spiritual issues. Thus, it can be said that developing psychological flexibility as a strategy in order to reduce FNE and psychological vulnerability indirectly can be a functional way. In other words, psychological flexibility might be combined with efforts to decrease the level of fear of negative evaluation and psychological vulnerability.

\section{Limitations}

There are several limitations of the current study that may provide further extension of the research. The first main limitation is cross-sectional design of the work; therefore, the results of the study should be contextually considered to generalize to other populations. The second, it is possible that there are some other mediators originating from more contextual conditions (e.g., family, institutions, and policy) rather than just intrapersonal or interpersonal processes. Therefore, some researchers strongly called for considering ecological systems theory to understand the role of mediators (Christens and Peterson 2012; Tanhan and Francisco 2019; Tanhan et al. 2020b). The researchers found the contextual factors to be important when examining college students' functioning and they called for future researchers to examine it with different samples (Tanhan et al. 2020a). Additionally, due to the fact that the present study relied on cross-sectional correlational statistics, no definitive generalizations and conclusions can be made with respect to causality.

\section{Implications and Future Directions}

The findings from the present study have implications for three main areas: research, practice, and education. To mention a few, mental health professionals as researchers can try to replicate this study with different clinical samples, adults, cultures, and geographical locations. They may use rigorous experimental and quasi-experimental studies, which are rare in the psychology field in Turkey (Bulus and Sahin 2019; Tanhan 2019, 2020). There are publicly available software packages to design efficient and rigorous (multilevel) experiments when mediation and moderation tests are involved (Bulus and Dong 2019). Mental health professionals may adopt PI processes (e.g., cognitive fusion) and psychological flexibility processes (e.g., defusion) through counseling and psychoeducation to utilize them to address psychological issues and enhance wellbeing. Mental health professionals as educators and supervisors are gatekeepers for future providers (Kalkan and Can 2019; Tanhan and Francisco 2019) who could give specific attention to help mental health providers-in-training to learn more about FNE, psychological vulnerability and especially ACT, and its underlying psychological flexibility and inflexibility models. Another implication is utilizing innovative qualitative research techniques to explore PI, FNE, and PV from participants' perspective. For example, Tanhan (2020) utilized Online Photovoice (OPV) to understand, advocate for, and address college students' biopsychosocial spiritual and economic issues during COVID-19. The researcher also strongly recommended future researchers, mental health providers, and educators to utilize Online Photovoice (OPV), as one of the innovative and recently improved, to understand and address psychopathology and wellbeing. Finally, mental health professionals may consider all these implications from an $\mathrm{ACT}$ perspective and through online venues considering the recent Coronavirus (COVID-19) and future pandemics.

\section{Conclusion}

Overall, we found that PI partially mediates the relationship between FNE and psychological vulnerability. Higher levels of FNE were related to higher levels of PI and psychological vulnerability. PI plays a dominant role in the progression of the psychological disorders, which makes PI a crucial construct, especially from ACT perspective. The findings contribute to the related literature in research, practice, and training.

Funding Authors had no external funding for this research. The authors financed all the charges for the current research. 


\section{Compliance with Ethical Standards}

Competing Interests The authors declare that they have no competing interests.

\section{References}

Akin, U. (2014). The predictive role of the self-compassion on psychological vulnerability in Turkish university students. International Journal of Social Sciences \& Education, 4(3), 693-701.

Akın, A., \& Eker, H. (2011). Turkish version of the psychological vulnerability scale: A study of validity and reliability. Paper presented at the 32th international conference of the stress and anxiety research society (STAR), July, 18-20, Munster, Germany.

Armbruster, D. J., Ueltzhöffer, K., Basten, U., \& Fiebach, C. J. (2012). Prefrontal cortical mechanisms underlying individual differences in cognitive flexibility and stability. Journal of Cognitive Neuroscience, 24(12), 2385-2399.

Arslan, G., Yıldırım, M., Tanhan, A., Buluș, M., \& Allen, K. A. (2020). Coronavirus stress and psychological health among adults: Exploring the effect of optimism-pessimism and psychological inflexibility. International Journal of Mental Health and Addiction. https://doi.org/10.1007/s11469-020-00337-6.

Baron, R. M., \& Kenny, D. A. (1986). The moderator-mediator variable distinction in social psychological research: Conceptual, strategic, and statistical considerations. Journal of Personality and Social Psychology, 51(6), 1173-1182. https://doi.org/10.1037/0022-3514. 44.

Becker, S. P., Langberg, J. M., \& Byars, K. C. (2015). Advancing a biopsychosocial and contextual model of sleep in adolescence: A review and introduction to the special issue. Journal of Youth Adolescence, 44, 239-270. https://doi.org/10.1007/s10964-0140248 -y.

Bentler, P. M., \& Bonet, D. G. (1980). Signifcance tests and goodness of fit in the analysis of covariance structures. Psychological Bulletin, 88, 588-606. https://doi.org/10.1037/0033-2909.88.3.588.

Bilge, F., \& Kelecioğlu, H. (2008). Psychometric properties of the brief fear of negative evaluation scale: Turkish form. Egitim Arastirmalari-Eurasian Journal of Educational Research, 32, 21 38.

Bond, F. W., Hayes, S. C., Baer, R. A., Carpenter, K. M., Guenole, N., Orcutt, H. K., Waltz, T., \& Zettle, R. D. (2011). Preliminary psychometric properties of the acceptance and action questionnaire-II: A revised measure of psychological inflexibility and experiential avoidance. Behavior Therapy, 42(4), 676-688.

Brown, M., \& Cudeck, R. (1993). Alternative ways of assessing model fit. In K. A. Bollen \& J. S. Long (Eds.), Testing structural equation models (pp. 136-162). Newbury Park: Sage.

Bulus, M., \& Dong, N. (2019). Bound constrained optimization of sample sizes subject to monetary restrictions in planning multilevel randomized trials and regression discontinuity studies. The Journal of Experimental Education. Advance online publication., 1-23. https:// doi.org/10.1080/00220973.2019.1636197.

Bulus, M., \& Sahin, S. G. (2019). Estimation and standardization of variance parameters for planning cluster-randomized trials: A short guide for researchers. Journal of Measurement and Evaluation in Education and Psychology, 10(2), 178. https://doi.org/10.21031/ epod.530642.

Button, K. S., Kounali, D., Stapinski, L., Rapee, R. M., Lewis, G., \& Munafò, M. R. (2015). Fear of negative evaluation biases social evaluation inference: Evidence from a probabilistic learning task. PLoS One, 10(4), 1-15.
Byrne, B. M., \& Campbell, T. L. (1999). Cross-cultural comparisons and the presumption of equivalent measurement and theoretical structure: A look beneath the surface. Journal of Cross-Cultural Psychology, 30, 555-574. https://doi.org/10.1177/ 0022022199030005001.

Christens, B. D., \& Peterson, N. A. (2012). The role of empowerment in youth development: A study of sociopolitical control as mediator of ecological systems' influence on developmental outcomes. Journal of Youth and Adolescence, 41(5), 623-635. https://doi.org/10.1007/ s10964-011-9724-9.

Crosby, J. M., Bates, S. C., \& Twohig, M. P. (2011). Examination of the relationship between perfectionism and religiosity as mediated by psychological inflexibility. Current Psychology, 30(2), 117-129.

Çetin, B., Doğan, T., \& Sapmaz, F. (2010). Olumsuz değerlendirilme korkusu ölçeği kısa formu'nun Türkçe uyarlaması: Geçerlik ve güvenirlik çalışması. Eğitim ve Bilim, 35(156), 205-216.

Choi, K. H., Lim, M. H., Ha, M., Sohn, J. N., Kang, J. W., Choi, Y. H., \& Cheong, H. K. (2015). Psychological vulnerability of residents of communities affected by the Hebei Spirit oil spill. Disaster Medicine and Public Health Preparedness, 10(1), 51-58.

Clark, D. O., Stump, T. E., Miller, D. K., \& Long, J. S. (2007). Educational disparities in the prevalence and consequence of physical vulnerability. The Journals of Gerontology Series B: Psychological Sciences and Social Sciences, 62(3), 193-197.

Cox, B. J., Enns, M. W., Walker, J. R., Kjernisted, K., \& Pidlubny, S. R. (2001). Psychological vulnerabilities in patients with major depression vs panic disorder. Behavior Research and Therapy, 39, 567573.

Dick, A. M., Niles, B. L., Street, A. E., DiMartino, D. M., \& Mitchell, K. S. (2014). Examining mechanisms of change in a yoga intervention for women: The influence of mindfulness, psychological flexibility, and emotion regulation on PTSD symptoms. Journal of Clinical Psychology, 70(12), 1170-1182.

Dryman, M. T., \& Heimberg, R. G. (2015). Examining the relationships among social anxiety, fears of evaluation, and interpretation bias. Cognitive Therapy and Research, 39, 1-12. https://doi.org/10.1007/ s10608-015-9694-4.

Ermis-Demirtas, H., Watson, J. C., Karaman, M. A., Freeman, P., Kumaran, A., Haktanir, A., \& Streeter, A. M. (2018). Psychometric properties of the multidimensional scale of perceived social support within Hispanic college students. Hispanic Journal of Behavioral Sciences, 40(4), 472-485. https://doi.org/10.1177/ 0739986318790733.

Fay, N., Page, A. C., Serfaty, C., Tai, V., \& Winkler, C. (2008). Speaker overestimation of communication effectiveness and fear of negative evaluation: Being realistic is unrealistic. Psychonomic Bulletin \& Review, 15(6), 1160-1165.

Furnham, A., \& Marks, J. (2013). Tolerance of ambiguity: A review of the recent literature. Psychology, 4(09), 717-728. https://doi.org/10. 4236/psych.2013.49102.

Galatzer-Levy, I. R., Burton, C. L., \& Bonanno, G. A. (2012). Coping flexibility, potentially traumatic life events, and resilience: A prospective study of college student adjustment. Journal of Social and Clinical Psychology, 31(6), 542-567. https://doi.org/10.1521/jscp. 2012.31.6.542.

Gaudiano, B. A., Schofield, C. A., Davis, C., \& Rifkin, L. S. (2017). Psychological inflexibility as a mediator of the relationship between depressive symptom severity and public stigma in depression. Journal of Contextual Behavioral Science, 6(2), 159-165. https:// doi.org/10.1016/j.jcbs.2017.04.010.

Gawda, B. (2017). Fear attachment as a predictor for mental inflexibility. Hypothesis on neural bases. NeuroQuantology, 15(4), 93-100. https://doi.org/10.14704/nq.2017.15.4.1081. 
Greco, L. A., Lambert, W., \& Baer, R. A. (2008). Psychological inflexibility in childhood and adolescence: Development and evaluation of the avoidance and fusion questionnaire for youth. Psychological Assessment, 20, 93-102. https://doi.org/10.1037/1040-3590.20.2. 93.

Gruebner, O., Lowe, S. R., Sampson, L., \& Galea, S. (2015). The geography of post-disaster mental health: Spatial patterning of psychological vulnerability and resilience factors in New York City after hurricane Sandy. International Journal of Health Geographics, 14(1), 16. https://doi.org/10.1186/s12942-015-0008-6.

Haktanir, A., Watson, J. C., Ermis-Demirtas, H., Karaman, M. A., Freeman, P. D., Kumaran, A., \& Streeter, A. (2018). Resilience, academic self-concept, and college adjustment among first-year students. Journal of College Student Retention: Research, Theory \& Practice. https://doi.org/10.1177/1521025118810666.

Hansen, M. S., Horjales-Araujo, E., \& Dahl, J. B. (2015). Associations between psychological variables and pain in experimental pain models. A systematic review. Acta Anaesthesiologica Scandinavica, 59(9), 1094-1102. https://doi.org/10.1111/aas. 12555.

Harris, R. (2009). ACT made simple: An easy-to-read primer on acceptance and commitment therapy. New Harbinger Publications.

Hayes, S. C., Luoma, J. B., Bond, F. W., Masuda, A., \& Lillis, J. (2006). Acceptance and commitment therapy: Model, processes and outcomes. Behaviour Research and Therapy, 44(1), 1-25. https://doi. org/10.1016/j.brat.2005.06.006.

Hayes, S. C., Strosahl, K., \& Wilson, K. G. (2012). Acceptance and commitment therapy: The process and practice of mindful change (2nd ed.). New York: The Guilford Press.

Hayes, A. F. (2018). Introduction to mediation, moderation, and conditional process analysis: A regression-based approach. New York: Guilford publications.

Hayes, A. F. (2013). Introduction to mediation, moderation, and conditional process analysis. New York: Guilford.

Hayes, S. C., Strosahl, K., \& Wilson, K. G. (2011a). Acceptance and commitment therapy: The process and practice of mindful change (2nd ed.). NewYork: The Guilford Press.

Hayes, S. C., Villatte, M., Levin, M., \& Hildebrandt, M. (2011b). Open, aware, and active: Contextual approaches as an emerging trend in the behavioral and cognitive therapies. Annual Review of Clinical Psychology, 7, 141-168. https://doi.org/10.1146/annurev-clinpsy032210-104449.

Heimberg, R. G., Brozovich, F. A., \& Rapee, R. M. (2010). A cognitivebehavioral model of social anxiety disorder: Update and extension. Social anxiety: Clinical, Developmental, and Social Perspectives, 2, 395-422. https://doi.org/10.1016/B978-0-12-375096-9.00015-8.

İkiz, E., İkiz, D., Asıcı., A., Savcı., A, \& Yörük, A. (2015). Problemli internet kullanımı ile üniversite yașamına uyum ilișkisi. Bartın University Journal of Faculty of Education, 4(1), 34-50. Retrieved from https://dergipark.org.tr/en/pub/buefad/issue/3816/51218

Kalkan, B., \& Can, N. (2019). Supervision in counselor education: Exploration of current status and standards in Turkey. Adiyaman Üniversitesi Eğitim Bilimleri Dergisi, 9(2), 271-290. https://doi. org/10.17984/adyuebd.

Kalkan, B., \& Griffiths, M. D. (2018). The psychometric properties of the online gambling symptom asessment scale (OGSAS). International Journal of Mental Health and Addiction, 1-11. https://doi.org/10. 1007/s11469-018-9981-x.

Karabulut, E. O., \& Bahadır, Z. (2013). Assessment of fear of negative evaluation levels and empathic tendency levels of national junior judo team. Journal of Physical Education \& Sports Science, 7(2), $108-115$.

Karaman, M. A., Aydın, G., \& Sarı, H. İ. (2020). Life balance and traumatic experiences in undergraduate students living near conflict zones. Current Psychology, 1-10. https://doi.org/10.1007/s12144020-00666-8.

Karaman, M. A., \& Watson, J. C. (2017). Examining associations among achievement motivation, locus of control, academic stress, and life satisfaction: A comparison of US and international undergraduate students. Personality and Individual Differences, 111, 106-110. https://doi.org/10.1016/j.paid.2017.02.006.

Kızıldağ, S., Zorbaz, S. D., Gençtanırım, D., \& Arıcı, F. (2012). Hacettepe üniversitesi öğrencilerinin psikolojik danışma yardımı almaya ve bu yardımın sunulduğu birimlere ilișkin görüşleri. Mersin Üniversitesi Eğitim Fakültesi Dergisi, 8(3), 185-196.

Kiamarsi, A., \& Abolghasemi, A. (2014). The relationship of procrastination and self-efficacy with psychological vulnerability in students. Procedia-Social and Behavioral Sciences, 114, 858-862.

Kline, R. B. (2015). Principles and practice of structural equation modeling. New York: Guilford publications.

Kornienko, O., \& Santos, C. E. (2014). The effects of friendship network popularity on depressive symptoms during early adolescence: Moderation by fear of negative evaluation and gender. Journal of Youth and Adolescence, 43(4), 541-553. https://doi.org/10.1007/ s10964-013-9979-4.

Krafft, J., Haeger, J. A., \& Levin, M. E. (2019). Comparing cognitive fusion and cognitive reappraisal as predictors of college student mental health. Cognitive Behaviour Therapy, 48(3), 241-252. https://doi.org/10.1080/16506073.2018.1513556.

Kurz, A. S., Bethay, J. S., \& Ladner-Graham, J. M. (2014). Mediating the relation between workplace stressors and distress in ID support staff: Comparison between the roles of psychological inflexibility and coping styles. Research in Developmental Disabilities, 35(10), 2359-2370. https://doi.org/10.1016/j.ridd.2014.06.003.

Landstra, J., Ciarrochi, J., Deane, F. P., \& Hillman, R. J. (2013). Identifying and describing feelings and psychological flexibility predict mental health in men with HIV. British Journal of Health Psychology, 18(4), 844-857. https://doi.org/10.1111/bjhp.12026.

Larson, R. W. (2011). Positive development in a disorderly world. Journal of Research on Adolescence, 21(2), 317-334. https://doi. org/10.1111/j.1532-7795.2010.00707.x.

Leary, M. R. (1983). A brief version of the fear of negative evaluation scale. Personality and Social Psychology Bulletin, 9(3), 371-375. https://doi.org/10.1177/0146167283093007.

Levin, M. E., MacLane, C., Daflos, S., Seeley, J. R., Hayes, S. C., Biglan, A., \& Pistorello, J. (2014). Examining psychological inflexibility as a transdiagnostic process across psychological disorders. Journal of Contextual Behavioral Science, 3(3), 155-163.

Levine, C. (2004). The concept of vulnerability in disaster research. Journal of Traumatic Stress, 17(5), 395-402. https://doi.org/10. 1016/j.jcbs.2014.06.003.

Makriyianis, H. M., Adams, E. A., Lozano, L. L., Mooney, T. A., Morton, C., \& Liss, M. (2019). Psychological inflexibility mediates the relationship between adverse childhood experiences and mental health outcomes. Journal of Contextual Behavioral Science, 14, 82 89. https://doi.org/10.1016/j.jcbs.2019.09.007.

Masuda, A., \& Tully, E. C. (2012). The role of mindfulness and psychological flexibility in somatization, depression, anxiety, and general psychological distress in a nonclinical college sample. Journal of Evidence-Based Complementary \& Alternative Medicine, 17(1), 66-71. https://doi.org/10.1177/2156587211423400.

McCracken, L. M., \& Vowles, K. E. (2007). Psychological flexibility and traditional pain management strategies in relation to patient functioning with chronic pain: An examination of a revised instrument. The Journal of Pain, 8(9), 700-707. https://doi.org/10.1016/j.jpain. 2007.04.008.

McDonnell, S., \& Semkovska, M. (2020). Resilience as mediator between extraversion, neuroticism, and depressive symptoms in 
university students. Journal of Positive Psychology and Wellbeing, 4(1), 26-40 Retrieved from http://journalppw.com/index.php/ JPPW/article/view/164.

McManus, F., Sacadura, C., \& Clark, D. M. (2008). Why social anxiety persists: An experimental investigation of the role of safety behaviours as a maintaining factor. Journal of Behavior Therapy and Experimental Psychiatry, 39(2), 147-161. https://doi.org/10.1016/ j.jbtep.2006.12.002.

Mehrabian, A. (1995). Theory and evidence bearing on a scale of trait arousability. Current Psychology, 14(1), 3-28. https://doi.org/10. 1007/BF02686870.

Mendoza, H., Goodnight, B. L., Caporino, N. E., \& Masuda, A. (2018). Psychological distress among Latina/o college students: The roles of self-concealment and psychological inflexibility. Current Psychology, 37(1), 172-179. https://doi.org/10.1007/s12144-0169500-9.

Morris, M. C., Kouros, C. D., Fox, K. R., Rao, U., \& Garber, J. (2014). Interactive models of depression vulnerability: The role of childhood trauma, dysfunctional attitudes, and coping. British Journal of Clinical Psychology, 53(2), 245-263. https://doi.org/10.1111/ bjc. 12038 .

Nonterah, C. W., Hahn, N. C., Utsey, S. O., Hook, J. N., Abrams, J. A., Hubbard, R. R., \& Opare-Henako, A. (2015). Fear of negative evaluation as a mediator of the relation between academic stress, anxiety and depression in a sample of Ghanaian college students. Psychology \& Developing Societies, 27(1), 125-142. https://doi. org/10.1177/0971333614564747.

Preacher, K. J., \& Kelley, K. (2011). Effect size measures for mediation models. Psychological Methods, 16(2), 93-115. https://doi.org/10. 1037/a0022658.

Raines, A. M., Oglesby, M. E., Unruh, A. S., Capron, D. W., \& Schmidt, N. B. (2014). Perceived control: A general psychological vulnerability factor for hoarding. Personality and Individual Differences, 56, 175-179. https://doi.org/10.1016/j.paid.2013.09.005.

Rapee, R. M., \& Heimberg, R. G. (1997). A cognitive-behavioral model of anxiety in social phobia. Behavior Research and Therapy, 35(8), 741-756.

Romero-Moreno, R., Losada, A., Marquez, M., Laidlaw, K., FernándezFernández, V., Nogales-González, C., \& Lopez, J. (2013). Leisure, gender, and kinship in dementia caregiving: Psychological vulnerability of caregiving daughters with feelings of guilt. Journals of Gerontology Series B: Psychological Sciences and Social Sciences, 69(4), 502-513. https://doi.org/10.1093/geronb/gbt027.

Sarıçam, H. (2015). The Turkish version of the social vulnerability scale: The study of validity and reliability. International Online Journal of Educational Sciences, 7(1), 190-202.

Satici, S. A., Kayis, A. R., \& Akin, A. (2013). Predictive role of authenticity on psychological vulnerability in Turkish university students. Psychological Reports, 112(2), 519-528. https://doi.org/10.2466/ 02.07.PR0.112.2.519-528.

Satici, B., Saricali, M., Satici, S. A., \& Eraslan, C. B. (2014). Social competence and psychological vulnerability as predictors of facebook addiction. Studia Psychologica, 56(4), 301-308.

Schermelleh-Engel, K., \& Moosbrugger, H. (2003). Evaluating the fit of structural equation models: Tests of significance and descriptive goodness-of-fit measures. Methods of Psychological Research Online, 8(2), 23-74.

Sertbaș, K. (2014). A research on the learned resourcefulness and psychological vulnerability levels of the school of physical education and sports students. International Online Journal of Educational Sciences, 6(2), 373-380.

Sinclair, V. G., \& Wallston, K. A. (1999). The development and validation of the psychological vulnerability scale. Cognitive Therapy and
Research, 23(2), 119-129. https://doi.org/10.1023/A: 1018770926615

Shenk, C. E., Putnam, F. W., Rausch, J. R., Peugh, J. L., \& Noll, J. G. (2014). A longitudinal study of several potential mediators of the relationship between child maltreatment and posttraumatic stress disorder symptoms. Development and Psychopathology, 26(1), 81-91. https://doi.org/10.1017/S0954579413000916.

Soares, D., \& Woods, K. (2020). An international systematic literature review of test anxiety interventions 2011-2018. Pastoral Care in Education, 1-24. https://doi.org/10.1080/02643944.2020.1725909.

Sobel, M. E. (1982). Asymptotic confidence intervals for indirect effects in structural equation models. In S. Leinhardt (Ed.), Sociological methodology (pp. 290-312). Washington, DC: American Sociological Association.

Tanhan, A. (2019). Acceptance and commitment therapy with ecological systems theory: Addressing Muslim mental health issues and wellbeing. Journal of Positive Psychology and Wellbeing, 3(2), 197-219. http://journalppw.com/index.php/JPPW/article/view/172.

Tanhan, A. (2020). COVID-19 sürecinde online seslifoto (OSF) yöntemiyle biyopsikososyal manevi ve ekonomik meseleleri ve genel iyi oluș düzeyini ele almak: OSF’nin Türkçeye uyarlanması. [Utilizing online photovoice (OPV) methodology to address biopsychosocial spiritual economic issues and wellbeing during COVID-19: Adapting OPV to Turkish.] Turkish Studies, 15(4), 1029-1086. https://doi.org/10.7827/TurkishStudies.44451.

Tanhan, A., \& Francisco, V. T. (2019). Muslims and mental health concerns: A social ecological model perspective. Journal of Community Psychology, 47(4), 964-978. https://doi.org/10.1002/jcop.22166.

Tanhan, A., \& Strack, R. W. (2020). Online photovoice to explore and advocate for Muslim biopsychosocial spiritual wellbeing and issues: Ecological systems theory and ally development. Current Psychology, 1-16. https://doi.org/10.1007/s12144-020-00692-6.

Tanhan, A., Karaman, M. A., \& Nalbant, A. (2020a). The effect of counseling on anxiety level from the perspective of ecological systems theory: A quasi-experimental pre-test - post-test control group study. International Journal of Psychology and Educational Studies, 7(3), 58-69. https://doi.org/10.17220/ijpes.2020.03.006.

Tanhan, A., Yavuz, K. F., Young, J. S., Nalbant, A., Arslan, G., Yıldırım, M., Ulusoy, S., Genç, E., Uğur, E., \& Çiçek, İ. (2020b). A proposed framework based on literature review of online contextual mental health services to enhance wellbeing and address psychopathology during COVID-19. Electronic Journal of General Medicine. https:// doi.org/10.29333/ejgm/8316.

Twohig, M. P. (2012). Acceptance and commitment therapy: Introduction. Cognitive and Behavioral Practice, 19(4), 499-507. https://doi.org/10.1016/j.cbpra.2012.04.003.

Watson, D., \& Friend, R. (1969). Measurement of social-evaluative anxiety. Journal of Consulting and Clinical Psychology, 33, 448-457. https://doi.org/10.1037/h0027806.

Webster, D. M., \& Kruglanski, A. W. (1994). Individual differences in need for cognitive closure. Journal of Personality and Social Psychology, 67(6), 1049-1062. https://doi.org/10.1037/0022-3514. 67.6.1049.

Weeks, J. W., Heimberg, R. G., \& Rodebaugh, T. L. (2008). The fear of positive evaluation scale: Assessing a proposed cognitive component of social anxiety. Journal of Anxiety Disorders, 22, 44-55. https://doi.org/10.1016/j.janxdis.2007.08.002.

Williams, K. E., Ciarrochi, J., \& Heaven, P. C. (2012). Inflexible parents, inflexible kids: A 6-year longitudinal study of parenting style and the development of psychological flexibility in adolescents. Journal of Youth and Adolescence, 41(8), 1053-1066. https://doi.org/10. 1007/s10964-012-9744-0.

Winton, E. C., Clark, D. M., \& Edelmann, R. J. (1995). Social anxiety, fear of negative evaluation and the detection of negative emotion in 
others. Behaviour Research and Therapy, 33(2), 193-196. https:// doi.org/10.1016/0005-7967(94)E0019-F.

Yadavaia, J. E., Hayes, S. C., \& Vilardaga, R. (2014). Using acceptance and commitment therapy to increase self-compassion: A randomized controlled trial. Journal of Contextual Behavioral Science, 3(4), 248-257. https://doi.org/10.1016/j.jcbs.2014.09.002.

Yavuz, F., Ulusoy, S., Iskin, M., Esen, F. B., Burhan, H. S., Karadere, M. E., \& Yavuz, N. (2016). Turkish version of acceptance and action
questionnaire-II (AAQ-II): A reliability and validity analysis in clinical and non-clinical samples. Klinik Psikofarmakoloji BülteniBulletin of Clinical Psychopharmacology, 26(4), 397-408. https:// doi.org/10.5455/bcp.20160223124107.

Publisher's Note Springer Nature remains neutral with regard to jurisdictional claims in published maps and institutional affiliations. 